\title{
An overview of gender inequality in EU universities
}

\author{
Rodrigo Rosa, Eileen Drew and Siobhán Canavan
}

\section{Introduction}

Gender equality has become an increasingly important policy requirement for academic institutions. Faced with enduring inequalities between female and male academics and administrators at all levels, university leaders have been charged with defining action strategies to ensure the effective implementation of structural measures to reduce and eliminate gender bias in their organisations. Universities play a crucial role in promoting gender equality and diversity; the last 20 years has produced a range of positive changes, through an enlarged pool of highly qualified women in academia and the wider labour market. Notwithstanding these positive developments, universities are structured around gender regimes where 'the current state of play is reflected in the macro politics of gender' (Connell 1987, 20). Gender regimes continue to impact on: who is recruited to do what work; what social divisions exist in the workplace and away from it, particularly in the domestic sphere; how emotional relations are conducted in the workplace; and how institutions relate to one another in relation to gender sensitivity. Universities are gendered since, like any other organisation, they are still defined by the fact that 'advantage and disadvantage, exploitation and control, action and emotion, meaning and identity, are patterned through and in terms of a distinction between male and female, masculine and feminine' (Acker 1990, 146).

\section{EU policy context}

Equality between women and men is one of the European Union's founding values, dating back to 1957 when the principle of equal pay for equal work became part of the Treaty of Rome. In accordance with the Treaty, the European Commission (2015) published the Strategic Engagement for Gender Equality 2016-19, setting out the framework for the Commission's future work towards improving gender equality. The strategic engagement focused on the following five priority areas:

1 increasing female labour market participation and equal economic independence;

2 reducing the gender pay, earnings and pension gaps and thus fighting poverty among women; 
3 promoting equality between women and men in decision-making;

4 combating gender-based violence and protecting and supporting victims;

5 promoting gender equality and women's rights across the world.

The document set out objectives in each of these priority areas and identified more than 30 concrete actions, reaffirming the European Commission's commitment to gender mainstreaming through a gender equality perspective integrated into all EU policies as well as into EU funding programmes. The strategic engagement also supported the implementation of the gender equality dimension in the Europe 2020 Strategy. Progress is reported annually and presented in annual reports on equality between women and men (for example, European Commission 2019a).

\section{EU policy framing and leading gender equality in research- initially STEM}

The new millennium saw the emergence of a number of significant reports and policy directions from the European Commission, from key actors such as the European Technology Assessment Network (ETAN), and cross-EU policy formulation on women and science and technology specifically. The strategic objective of the European Research Area (ERA) required action to promote gender equality in science, recognising the need to promote research by, for and about women to optimise the value that they could contribute to European society (European Commission 2001).

The ETAN Report (European Commission 2000) described the continuous leakage of women at each level of the academic ladder, on which women comprised less than 10 per cent of the leaders in the 'scientific system', despite the fact that half the Science, Technology, Engineering and Mathematics (STEM) graduates were women. It pinpointed the forms of discrimination, often unconscious, against women and identified the key problems faced by women in scientific careers. The flawed operation of the peer review system was highlighted along with the low level of engagement by women in shaping scientific policy and setting the agenda in the top committees of the EU and of member states. The report advocated a sustainable improvement of women's standing in science and research, requiring a significant transformation of science and scientific institutions (European Commission 2000).

The WIRDEM (Women in Research Decision-Making) expert group report (2008) identified nomination procedures, cultural barriers and funding limitations as hindering factors in the progress of women in their academic careers. It reviewed member states' policies and existing procedures for evaluating and promoting researchers to senior positions, outlining examples of good practice at national and institutional levels and proposed recommendations for more targeted actions at the European level, arguing that European research and higher education institutions could no longer afford to exclude potential innovators.

The Helsinki Group Gender in Research and Innovation was established by the European Commission in 1999 as an advisory group to help to overcome 
this disadvantage of women in STEM. In 2017, the Helsinki Group was transformed into the Standing Working Group on Gender in Research and Innovation (SWG GRI) of the European Research Area and Innovation Committee (ERAC). It consists of representatives from member states, associated countries and the European Commission. The group sought to integrate a gender dimension into the mainstream of the research policy process, starting with the benchmarking of national research policies, in which the gender dimension should be integrated in all the indicators to be developed. The overall objective of the Group is to advise the Council and the European Commission on policies and initiatives on gender equality in Research and Innovation, for the benefit of scientists, research institutions, universities, businesses and society at large.

In response to these gender issues, a European Research Area (ERA) Survey pointed to actions that research organisations could take, such as recruitment and promotion measures, targets to ensure gender balance in recruitment committees, flexible career trajectories (for example, schemes after career breaks), work-life balance measures and support for leadership development (European Commission 2015). According to their survey conducted in 2014, around 36 per cent of research performing organisations had introduced Gender Equality Plans (GEPs) in 2013. The gendering of indicators on human resources in science was to be tackled in three ways: top-down (the introduction of the gender variable in the collection of data on human resources in research and development), bottom-up (organising existing data collected at national level, and developing indicators on the basis of this data), and the gendering of the benchmarking exercise. In summary:

European research policy has been a model for 'gender mainstreaming' (consideration of gender in all aspects of policy) since 1999. . . Some Member States were already paying attention to the issue, while others took their lead from the Commission, with more or less enthusiasm depending on their cultural and historical backgrounds. ... Over the years, three research Framework Programmes supported activities to increase the number and role of women scientists, as well as to mainstream gender in the content of research. Despite the fact that the momentum for gender equality had been slowing down, progress towards a European Research Area 'by/for/on women' was continuing, albeit more slowly than previously. Therefore, a new policy direction was decided upon by the Commission. The new focus for activities was on the research institutions and organisations where women in science work, rather than just on the women themselves. 'Fixing the administration' became the new objective.

(European Commission 2010, 12)

The stocktaking of Women in Science policy by the European Commission 19992009 illustrates how the European Commission 'provided the impulse, and acted as a catalyst and multiplier, shaping and coordinating the efforts' (European Commission 2010,7). 
Despite the global feminisation of the third-level student population as a striking feature of higher education over the last 40 years, women are not progressing at the same rate as men in their academic careers. At the leadership level, women accounted for only 24 per cent of grade A professors (professorial chairs) and 22 per cent of heads of institutions in the higher education sector across the EU in 2017, thereby indicating the need to take action and identify good practices in the sector to attract and promote women in research and innovation (European Commission 2019b). The European Commission's SHE figures 2018 reveal that a range of gender differences and inequalities persist in research and innovation. Whilst women were once under-represented at doctoral level, in 2018 they made up 48 per cent of doctoral graduates in the EU-28. However, in 2018, women accounted for just 29 per cent of doctoral graduates in engineering, manufacturing and construction and only 21 per cent of those graduating from computing (European Commission 2019b).

Striking gender inequalities persist in career advancement and participation in academic decision-making. Despite significant progress in their level of education relative to men in recent decades, women are increasingly under-represented as they move up the stages of an academic career (Figure 1.1). The pool of female graduate talents has increased, but the availability of female role models as careers progress is still sparse, reflecting the differential in career progression by women and men. Despite the growth in numbers of female undergraduates and postgraduates, the career trajectories of men and women in academia continue to show significant inequalities. Gender trajectories take the form of a scissors-shaped trend, which shows a significant loss of female potential after the award of doctoral degrees. Work-life imbalance is one among the major barriers to gender equality

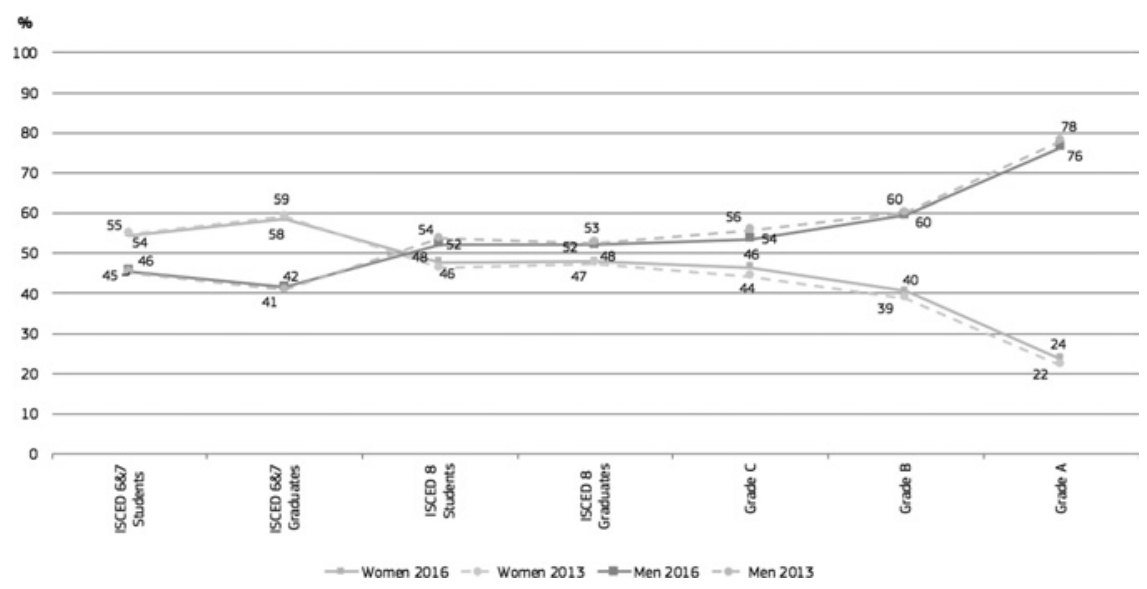

Figure 1.1 Percentage of men and women in a typical academic career, students and academic staff (EU-28) 2013-2016

Source: SHE Figures, European Commission 2019 
since it still most frequently impedes the career advancement of women in academia, 13 per cent of whom work part-time, compared with 8 per cent of male academics (European Commission 2019b). Women's representation diminishes significantly during academic careers so that the percentage of women academic staff at grade A (7.4\%) is less than half of the corresponding proportion for men $(16.7 \%)$. This results in: far fewer female academics in more powerful positions; a gender pay gap; gender imbalance in the composition of research teams; and a higher proportion of women, especially those in junior academic positions or other positions, relying on third-party funding, employed on precarious working contracts (European Commission 2019b). These gender differences are even more acute among students/staff in science and engineering disciplines (Figure 1.2).

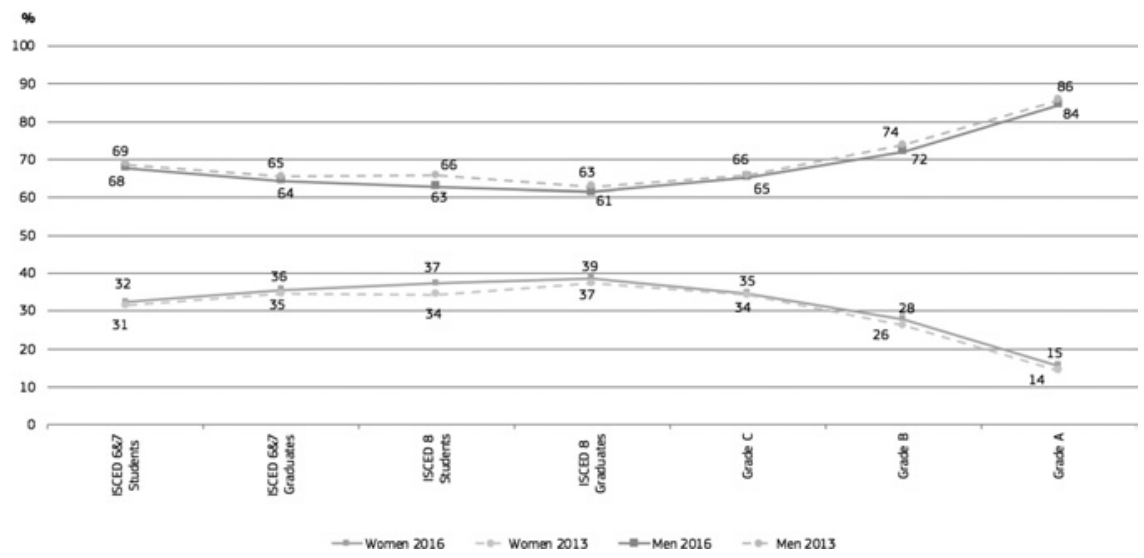

Figure 1.2 Percentage of men and women in a typical academic career in science and engineering, students and academic staff (EU-28) 2013-2016

Source: SHE Figures, European Commission 2019

Internationally, the leaky pipe metaphor (Alper 1993) has been coined to represent the progressive decrease in the presence of women in academia at each career stage and this pattern is all too evident in the SHE Scissors Diagrams (Figures 1.1 and 1.2). UPGEM (Understanding Puzzles in the Gendered European Map) noted with concern that well-qualified female scientists often leave the research system prematurely and those who stay rarely, or never, reach the top-level positions (grade A professors) or achieve distinguished careers in research and development in the same way as their male counterparts do (UPGEM 2008). The underlying causes of this phenomenon have been studied extensively across the EU with the general conclusion that contemporary academic careers, through various mechanisms, reward members of the male gender (Badaloni et al 2008). Policies for the recruitment, retention, promotion and leadership of researchers in EU research bodies often affect the career progression of female researchers adversely, as 
illustrated by the differential exit of female researchers at, or after, their doctoral studies across the EU. Moreover, when it comes to appointing skilled professionals to decision-making positions in national research and academic institutions, women are already at a disadvantage because of their smaller numbers, which in turn prevents them from participating more equitably in the highest echelons of their institutions.

\section{US policy interventions for gender equality in STEM}

The need for institutional transformation, involving organisational and cultural change within research bodies and universities was first recognised outside Europe, most visibly in US initiatives. In 1981, the US Congress adopted the National Science Foundation Authorization and Science and Technology Equal Opportunities Act. Under this law, the Director of the National Science Foundation (NSF) is required to send Congress and government officials a statistical report on the numbers of women and other minorities (sic) in employment and training in the science and engineering sectors every two years. Since 2001, the US National Science Foundation's pioneer ADVANCE (Increasing the Participation and Advancement of Women in Academic Science and Engineering Careers) programme has successfully encouraged major universities in the US to change their policies and procedures for recruitment, retention, tenure and promotion, in order to improve the local gender climate and the situation of women faculty in STEM disciplines (Bilimoria and Liang 2012).

The academic institutions funded through the five-year ADVANCE Institutional Transformation Awards, defined and implemented comprehensive customised action plans to address institutional structures and organisational barriers. This was undertaken through supports to women academics' career development, leadership and empowerment initiatives, work-life balance and the engagement of institutions' academic governance at the highest level. Significant results were achieved by many of the higher education institutions through the development of best practices, effective networking and dissemination strategies, and innovative transformational approaches.

These efforts provided useful examples of successful practices for the EUfunded FP7 INstitutional Transformation for Effecting Gender Equality in Research (INTEGER) partnership (2011-2015), which developed links with US institutions and practitioners involved in the ADVANCE programme (for example, the University of Michigan), and the knowledge and experience gained by them was available to the INTEGER project partners.

\section{EU structural change-driven policy interventions in academia}

In its report Structural Change in Research Institutions, the European Commission (2012a) argued that gender-aware management of universities and research 
organisations would have a positive impact on policies and practices in recruitment, promotion and retention of both women and men, ultimately benefiting the quality of the research itself. Furthermore, the report stressed that progress in integrating gender in research and innovation requires firm and sustained top-level commitment. The recommendations for different constituent institutions, aimed at universities and scientific institutions, are as follows:

1 ensure a gender dimension is integrated into the undergraduate and postgraduate curricula, across the university (particularly in engineering and science);

2 adopt an Equality Plan and include audit results (gender disaggregated statistics) in annual reports. These should include the gender pay gap, staff statistics and senior committee membership;

3 sign up to and follow a set of good practices;

4 up-skilling for career development and content of research.

Founded in 2002, the League of European Research Universities (LERU) is an association of 21 leading research-intensive universities that share the values of high-quality teaching within an environment of internationally competitive research. In 2012, LERU issued recommendations for governments, funders of research, academic publishers and, most notably, universities to address gender deficits through embarking upon actions. These sought commitment at the top and throughout the institution to gender equality; development or implementation of a gender strategy and/or action plan with the support of all divisions and levels within the university; ensuring sufficient funding for all gender equality activity to enable long term planning of gender equality activity to achieve structural change; selecting the right mix of gender-specific career development measures and gender-neutral work-life balance measures; transparency, accountability and monitoring to ensure successful implementation and improvement where needed; and promoting and supporting a gender dimension in research, taking into account the specificities of particular research fields (LERU 2012).

In the European Commission's SHE figures 2018, the European Commissioner for Research, Science and Innovation stated:

There is progress but it is slow. And we still have a long way to go to achieve full gender equality. . . . We cannot sit back and assume that having planted the seeds of gender equality, the positive trends will continue. . . What we need is a complete cultural change, which requires systematic and coordinated actions, education and strong political commitment by all actors involved.... If we want to take scientific excellence to the next level; if we want to deliver science-based solutions to the many urgent and pressing global challenges, we need all talents in play. . . . I therefore invite you all to act as ambassadors of change to close the gender gap. Together, we will succeed.

(European Commission 2019b, 4) 


\section{Gendered research and funding}

Research funding success rates in most European countries are lower for women than for male team leaders by an average of 3 per cent (European Commission 2019b). Although this gap has narrowed over time, gender differences persist. Across the EU, the gender gap (computed as men's success rate minus women's success rate) has decreased by 2.4 per cent since 2010 , though men continue to have a higher success rate than women, outstripping them by 4.4 per cent in funding applications to national programmes (with 31.8 per cent male and 27.4 per cent female success rates respectively). There are, however, important national variations within the EU-28, with gender gaps ranging from 12.9 to 0.6 per cent (European Commission 2014).

Linked to the under-representation of women in funded research, female researchers remain under-represented in scientific authorship. Less than one-third (32\%) of all publications named a woman as corresponding author in 2017 (European Commission 2019b). This is underlined by a relentless absence of a firm gender perspective in most research 'in the 2013-2017 period, 1.79 per cent of all research in the EU-28 included a sex or gender dimension in its research content' (European Commission 2019b, 176).

LERU identified the lack of a gender dimension in research as one of four priority areas in which universities could usefully undertake gender actions (LERU 2012). In 2015, LERU launched an advisory paper Gendered Research and Innovation: Integrating Sex and Gender Analysis into the Research Process (LERU 2015), showing how gendered research and innovation is an under-recognised issue, too often ignored in research design, process, content and implementation. LERU highlighted the role of social sciences and humanities (SSH) research in attending to these processes and recommended that: LERU universities lead by example; governments include a gender dimension in research policies and programmes; and that the approach taken at EU level is continued and strengthened. The importance of journals setting standards for the inclusion of information on gender in research, along with clear guidelines for authors, were also identified as positive actions (LERU 2015).

Today, university leaders face the challenge of achieving sustainable and institution-wide change towards gender equality in an age when neoliberal transformations have created a governance model for universities that prioritises economic rationality (see Chapters 2 and 11). Women have demonstrated their scholarly excellence alongside their male counterparts, yet the overt and subtle gender mechanisms identified throughout this book prevent them from making significant progress up the career ladder in an increasingly competitive academic environment, which often privileges individual success over collaborative effort. Furthermore, managerialist tools, such as the demanding measurement of scientific excellence through the ' $h$ index', create increasing challenges to achieving gender sensitivity in academia (Paradeise et al 2009) (see Chapter 8). 


\section{Ending gender inequalities in academia and research: policy developments}

The European Union explicitly committed to mainstreaming gender in its Communication on women and science (European Commission 1999) and the gender mainstreaming principle was integrated for the first time into the Fifth Framework Programme (FP5), running from 1998 to 2002. Gender equality in science was understood in terms of three dimensions: to promote research 'by, for and about women'. During the course of FP5, the European Commission required that studies produce a gender impact assessment (GIA) to monitor the way in which gender issues were being addressed (European Commission 2001; Braithwaite 2001).

It was in the context of Framework Programme 6 (FP6) (2002-2006) that gender mainstreaming was formally integrated into the EU research policy. Two main objectives were established: a target of 40 per cent women's representation on committees, groups and panels and the integration of the gender dimension in research content. Based on the results and recommendations of the FP5 Gender Impact Assessment, in FP6 the European Commission adopted guidelines for proposals to ensure better attention to the gender dimension in research. Gender monitoring studies were planned and implemented so that the results could feed into the next framework programme. Gender Action Plans were made mandatory for networks of excellence and integrated projects. In addition, under FP6, a total of 39 genderspecific projects exploring this theme were funded (European Commission 2009). Those projects analysed the factors that facilitated or inhibited the incorporation of the gender dimension in research, developed practical tools to help researchers and produced recommendations to help scientists, funding agencies, research organisations, governments and other stakeholders. The aim was to ensure that sex and gender differences were given the attention that they deserved. However, monitoring reports showed that, despite the significant contribution made in FP6, in terms of progress towards gender equality, there remained much scope for improvement. Hence, more and continued efforts were required to realise further progress towards meeting the objectives of FP6 (European Commission 2008).

A study analysing the implementation of gender mainstreaming in FP6 identified significant resistance to gender initiatives within the Directorate General for Research and Innovation. This contributed to addressing obstacles to effective implementation (Mergaert and Lombardo 2014). These included explicit and implicit, individual and institutional, resistance such as a lack of adequate capacity-building for gender mainstreaming. This in turn revealed institutional resistance by not prioritising gender mainstreaming and the fact that the voices of gender experts were not allowed any significant influence on the policy process.

In FP7 (2007-2013) the EU reinforced efforts to support gender research stressing that:

adequate attention should be paid to gender mainstreaming, as well as to, inter alia, working conditions, transparency of recruitment processes, and 
career development as regards the researchers recruited on projects and programmes funded under the actions of this programme.

(Council of the European Union 2006, 250)

Numerous projects addressing this issue were funded during FP7. One notable example was the funding of the expert group Innovation through Gender, convened by the European Commission in 2011. The group involved more than 60 experts from across Europe, the US and Canada. Its goal was twofold: to provide scientists and engineers with practical methods for sex and gender analysis and to develop case studies as concrete illustrations of how sex and gender analysis leads to new ideas and excellence in research. The results, initiated at Stanford University in 2009, were published in Gendered Innovations (Schiebinger 2013). The Gendered Innovations website is a key source for scientists seeking to integrate a gender dimension into their research. More recently, the European Commission, under the H2020 programme, decided to provide funding to the network with the aim of updating and expanding Gendered Innovations/Innovation Through Gender (European Commission Decision C (2019) 4575 of 2 July 2019).

Ending gender inequalities in academia has been one of the priorities of $A$ Reinforced European Research Area Partnership for Excellence and Growth (ERA) (European Commission 2012b), a key objective of which was to remove barriers to recruitment, retention and career progression for female researchers, alongside addressing a better gender balance in decision-making and strengthening the gender dimension in research programmes. Member states were encouraged to correct these inequalities by creating a legal and policy environment that created incentives for institutional change in research, through Gender Equality Plans (GEPs) (European Commission 2012b, 13). Other examples of gender equality provisions are integrated into national excellence evaluation frameworks, as illustrated by Germany's Excellence Initiative (Riegraf and Weber 2017).

The implementation of national GEPs is crucial in tackling gender inequalities in academia and helps to explain variations among EU member states. In 2016, GEP implementation ranged from under 20 per cent in Slovakia and Bulgaria to 60 per cent in Ireland and over 90 per cent in Sweden, Germany and the United Kingdom (European Commission 2019b, 111). Despite this variation, the implementation of GEPs is not unrelated to progress achieved at university governance level over the last decade. Among members of the European University Association (EUA), the proportion of women rectors has increased slowly, from 9.5 per cent in 2010 to 13 per cent in 2013 and 14.3 per cent in 2019. Women account for one-quarter of the vice-rectors in 2019 (Jorgensen 2019). According to the SHE figures 2018 (European Commission 2019b), women made up more than one-quarter $(27 \%)$ of educational institution board members across the EU in 2017 and their representation among heads of institutions in the higher education sector increased slightly from 20.1 per cent in 2014 to 21.7 per cent in 2017. In contrast, data from the EUA suggest that, while barriers to women's career advancement hinder their access to the top level of the academic hierarchy, 
as rectors and presidents, there is more gender equality when a professorship is not a requirement for high-level management positions, such as head of international office, human resources, communication, research or quality assurance (Jorgensen 2019). More gender balanced top management leadership teams are a foundational step in achieving gender-sensitivity in higher education, since the success of any policy intervention is highly dependent on how university leaders engage in promoting gender equality (see Chapter 11).

In addition, tools for the integration of gender in research were also developed under FP7, including the Recommendations for Integrating Gender Analysis into Research (IGAR) tool, developed as part of the GENDER-NET project. GENDER-NET produced a set of indicators to measure the degree of integration of gender analysis into research, drawing upon the Yellow Window (a gender equality consultancy company) toolkit and training for EU gender-funded research (European Commission 2011). This widely used toolkit provides an overall introduction to gender in research and practical tools on how to make research gender sensitive, with examples of gendered contents in different disciplines, such as health, energy, nanosciences, environment, transport. Other projects funded under FP7 produced a set of guidelines and recommendations for the integration of a gender dimension of science. One example is the GenSET project, aimed at developing practical ways in which gender knowledge and gender mainstreaming expertise could be incorporated within European science institutions. In 2010, GenSET published recommendations for action on the gender dimension in science (Buitendijk et al 2010).

Similar tools were produced by the Gendering the Academy and Research: Combating Career Instability and Asymmetries (GARCIA) project which covered the integration of a gender-sensitive approach in teaching and research and the Effective Gender Equality in Research and the Academia (EGERA) project report on Good Practices of Gender Sensitive Research: Guidelines and Information Sheet, which provides background and criteria for identifying good examples of gender-sensitive research initiatives and the INstitutional Transformation for Effecting Gender Equality in Research (INTEGER) project Tools for Action. In the EU-Horizon 2020 programme, the gender dimension is explicitly integrated from the outset in many of the specific calls. Under this research framework initiative, the Systemic Action for Gender Equality Project (SAGE) provided the design and implementation of tailored GEPs structured around a wheel model for GEPs focusing on four quadrants: institutional governance, engendering knowledge, career progression and work-life balance (Figure 1.3).

GEPs were developed by SAGE implementing partners: University Institute of Lisbon (ISCTE-IUL), International University of Sarajevo (IUS), Kadir Has University, Istanbul (KHAS), Sciences Po Bordeaux (SciPo) and University of Brescia (UNIBS). The SAGE wheel model includes measures to achieve equality in each of the four quadrants. While identifying the causes of problems that occurred throughout the SAGE project's life and ways to avoid those problems in later project stages, SAGE partners have learned important lessons. First, it 


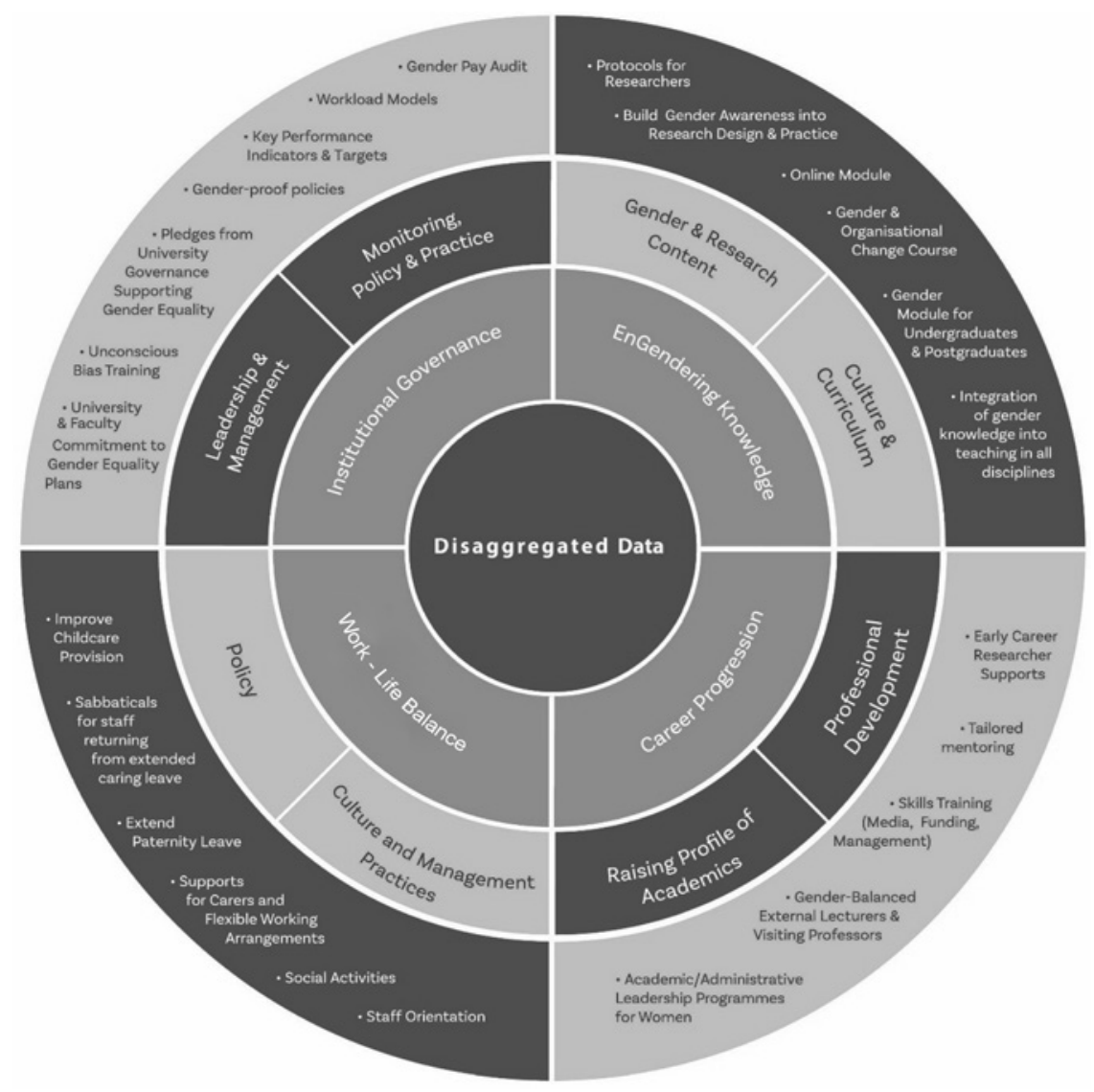

Figure 1.3 SAGE project Gender Equality Plan (GEP) wheel model

is crucial to avoid gender binaries to address intersectional diversity. Second, actions must be data driven, designed to be gender neutral, tailored to the micro or macro environment in which they operate and strategically designed to align with the institution's core values. Third, it is important to involve men as champions/ active participants in the transformational change process. Fourth, actions need the support from top level as well as key allies, for example, Human Resources and Equality/Diversity offices, to influence gender-related policy and overcome resistance. Fifth, it is important to apply an active communication strategy, conveying information on actions and their benefits to the widest possible community of stakeholders. Sixth, while responding to the local context and specific needs, acting at institutional and school/departmental levels, making use of and/ or extending existing training and development opportunities, GEPs can prioritise 
unconscious bias training. Finally, it is crucial to pay attention to the unintended consequences of interventions, since a measure that seems beneficial for a portion of the target group, may not be for others. For example, during the implementation of the GEP at ISCTE-IUL, heads of departments involved in the elaboration of new class schedules needed to ensure that a redistribution of teaching hours, sensitive to the situation of parents with young children, would not adversely impact their colleagues without young children.

\section{Conclusion}

As this chapter demonstrates, the path towards gender equality in higher education has been neither simple nor linear. Creating a gender-sensitive university demands both behavioural and attitudinal change, both of which can be guided by innovative thinking, legislative frameworks and a commitment to change through data gathering, monitoring, training, leadership, networks and synergies of the most unexpected kinds. Challenging the prevailing wisdom, especially in institutions with a long history, can be lonely work, as the chapters in this book testify. The aim of this book is to put down a marker for the journey towards a gendersensitive university to avoid this aspiration becoming a tautological dream.

A chronological outline of the emergence of gender-equality policies in higher education institutions and the drive towards the creation of a gender-sensitive academia forms the backbone of this book, in which Chapter 1 (Rosa, Drew and Canavan) has set the scene. Chapters 2 to 9 deal with the ongoing obstacles, barriers and issues that characterise gender-insensitive universities. Chapters 10 to 14 challenge the continued gendering of the social and academic order. They promote mechanisms to interrogate and address this, thereby envisioning the emergence of gender-sensitive institutions.

Chapter 2 (Rosa and Clavero) outlines the challenges of neoliberalism and precarity for achieving gender sensitivity and documents the contributions of intersectionality and feminist research. Chapter 3 (Mathias Wullum Nielsen) deals with gendered recruitment, followed by Chapter 4 (Kinahan, Dunne and Cahill), which elaborates on gendered career progression. Chapter 5 (Drew and Marshall) expands on the gendered reality of work-life balance as being more aspirational than real. Further chapters demonstrate and question the fluidity of gendered institutions leading to policy interventions that could influence their gender sensitivity. Instrumental in this process is the need to heighten awareness of sexual harassment and violence, addressed in Chapter 6 (Paoletti, Quintin, Gray-Sadran and Squarcioni) through a detailed analysis of a French campus-based case study. Chapter 7 highlights the importance of conducting gender pay gap analyses (Galligan, McMahon and Millar) in higher education institutions.

The significance of men and their masculinities, in shaping and perpetuating a fixed-gender regime in academia, is examined in Chapter 8 (Hearn), whilst the complex terrain of unconscious bias is explored and exposed in Chapter 9 (Gvozdanović and Bailey). Change management for gender equality represents a 
critical process in the creation of gender-sensitive institutions and is addressed in Chapter 10 (Bailey and Drew). Fundamental to this transition is the future leadership of universities. Chapter 11 (Power) places this in a wider context which embraces alternative models of leadership, better orientated to gender sensitivity. In Chapter 12 Doona explores the vital role of research funding as a driver towards achieving gender equality in academia. The potentially destructive, subtle actions and inactions that can impede the academic careers of women are addressed in Chapter 13 (Husu). Finally, Chapter 14 (Bencivenga and Drew) represents the composite learning from SAGE partners and other gender experts, whilst looking ahead to a future in which all higher education institutions are gender-sensitised and progressive in their pursuit of research innovation and excellence.

\section{References}

Acker, J. (1990) Hierarchies, jobs, bodies: A theory of gendered organizations, Gender \& Society, 4 (2), 139-158, doi.org/10.1177/089124390004002002

Alper, J. (1993) The pipeline is leaking women all the way along, Science, 260, 409-411, doi.org/10.1126/science.260.5106.409

Badaloni, S., Drace, C., Gia, O., Levorato, M. and Vidotto, F. (eds) (2008) Under-representation of women in science and technology, Cleup, Padova.

Bilimoria, D. and Liang, X. (2012) Gender equity in science and engineering: Advancing change in higher education, Routledge, Abingdon, Oxon.

Braithwaite, M. (2001) Gender mainstreaming in the European commission: Explaining the roller coaster of progress and regression, Engender, DUP, Brussels.

Buitendijk, S., Revuelta, C. C., Corda, D., Flodström, A., Holdcroft, A., Hunter, J., James, A., Kitchen, N., Schraudner, M., Sjørup, K., Rice, C. and Tarrach, R. (2010) Recommendations for action on the gender dimension in science. Available at: www.genderportal. eu/sites/default/files/resource_pool/genSET_consensus_report.pdf

Connell, R. (1987) Gender and power: Society, the person and sexual politics, Polity Press, Cambridge.

Council of the European Union (2006) Council decision concerning the specific programme: 'Ideas' implementing the seventh framework programme of the European community for research, technological development and demonstration activities (2007 to 2013), Official Journal of the European Union, L400, 243-271.

European Commission (1999) 'Women and science' mobilising women to enrich European research, European Commission, Brussels. Available at: https://ec.europa.eu/research/ swafs/pdf/pub_gender_equality/g_wo_co_en.pdf

European Commission (2000) Science policies in the European Union-promoting excellence through mainstreaming gender equality, report from the ETAN (European Technology Assessment Network) Expert Working Group on Women and Science, European Commission, Luxembourg.

European Commission (2001) Women and science: The gender dimension as a leverage for reforming science, SEC(2001)771, 15 May. Available at: www.cordis.lu/improving/ women/documents.htm

European Commission (2008) Benchmarking policy measures for gender equality in science, DG Research, EUR 23314, Capacities/Science in Society, Unit L4-Scientific culture and gender issues, European Commission, Luxembourg. 
European Commission (2009) Monitoring progress towards gender equality in the sixth framework programme synthesis report, European Commission, Luxembourg.

European Commission (2010) Stocktaking 10 years of 'women in science' policy by the European Commission 1999-2009, (eds M. Marchetti and T. Raudma), ERA, Science in Society, European Commission, Luxembourg.

European Commission (2011) Toolkit gender in EU-funded research, European Commission, Luxembourg.

European Commission (2012a) Structural change in research institutions: Enhancing excellence, gender equality and efficiency in research and innovation, European Commission, Luxembourg.

European Commission (2012b) A reinforced European research area partnership for excellence and growth. Available at: https:/ec.europa.eu/digital-single-market/en/news/ reinforced-european-research-area-partnership-excellence-and-growth

European Commission (2014) European research area-facts and figures 2014, European Commission, Luxembourg.

European Commission (2015) Strategic engagement for gender equality 2016-2019, European Commission, Brussels. Available at: http://ec.europa.eu/justice/genderequality/ document/files/strategic_engagement_en.pdf

European Commission (2019a) 2019 report on equality between women and men in the $E U$, European Commission, Luxembourg.

European Commission (2019b) SHE figures 2018, European Commission, Luxembourg.

Jorgensen, T. (2019) Gender equality in Europe's universities. SAGE Final Event, 10 July, (unpublished), Brussels.

LERU (2012) Women, research and universities: Excellence without gender bias, League of European Research Universities, Leuven.

LERU (2015) Gendered research and innovation: Integrating sex and gender analysis into the research process, League of European Research Universities, Leuven.

Mergaert, L. and Lombardo, E. (2014) Resistance to implementing gender mainstreaming in EU research policy, in E. Weiner and H. MacRae (eds), The persistent invisibility of gender in EU policy, European integration online papers (EIoP), 1 (18), 1-21, doi:10. $1695 / 2014005$

Paradeise, C., Reale, E., Bleiklie, I. and Ferlie, E. (2009) University governance: Western European comparative perspectives, Springer, Dordrecht.

Riegraf, B. and Weber, L. (2017) Excellence and gender equality policies in neoliberal universities. Gender and Research, 18 (1), 92-112, doi.org/10.13060/25706578.2017.18.1.351

Schiebinger, L. (2013) Gendered innovations: How gender analysis contributes to research, EU Publications Office, Luxembourg.

UPGEM (2008) Draw the line! UPGEM International Conference. Papers, Proceedings and Recommendations, in C. Hasse, S. Trentermoller and A. Sinding (eds), University of Aarhus, Aarhus. Available at: https://cordis.europa.eu/docs/projects/files/518/518048/ 116810421-6_en.pdf

WIRDEM (2008) Mapping the maze: Getting more women to the top in research, European Commission, Brussels. Available at: http://ec.europa.eu/research/science-society/document_ library/pdf_06/mapping-the-maze-getting-more-women-to-the-top-in-research_en.pdf 